\title{
Estamos voando sobre uma bola de fogo: movimento, multiplicidade e realidade cotidiana
}

\author{
We are flying over a fireball: \\ movement, multiplicity and everyday reality \\ Estamos volando sobre una bola de fuego: \\ movimiento, multiplicidad y realidad cotidiana
}

Eduardo Simonini ${ }^{2}$

\begin{abstract}
Resumo: O presente trabalho pretende pensar a realidade cotidiana como uma dimensão em multiplicidade que se abre ao diverso e à diferença. Para desenvolver esta questão, são problematizadas duas concepções sobre a realidade: uma que defende que esta pode ser compreendida como uma unidade totalizável em sua imobilidade, e outra que considera por realidade uma dinâmica em movimento sempre em vias de novas transformações. Na proposta de seguir esses dois modelos de realidade, este trabalho se utiliza, como um cordão de Ariadne, da ação de acompanhar alguns usos que foram feitos, nos últimos dois milênios, da imagem do Diabo. Desdobrando esses diferentes usos no conversar com as teorias de Platão, Hegel, Nietzsche, Deleuze e Guattari, este trabalho defende que as realidades cotidianas são forjadas em encontros incertos a agenciarem misturas que, devindo em multiplicidade, não se filiam a um projeto universal.
\end{abstract}

Palavras-chave: Realidade. Multiplicidade. Cotidiano.

Abstract: This work intends to think on the everyday reality as a dimension in multiplicity that opens itself to the diversity and the difference. In order to develop this question, two conceptions about reality are problematized: one that argues it can be understood as a totalizable unit in its immobility, and another that considers by reality, a dynamic in movement, always in the process of new transformations. In the proposal to study these two models of reality, this work uses, as an Ariadne's thread, the action to follow some uses that have been made, in the last two millennia, of the Devil's image. Unfolding these different uses in connection with the theories of Plato, Hegel, Nietzsche, Deleuze, and Guattari, this work argues that the everyday realities are forged in uncertain encounters, mixing up in multiplicity, and not fitting into a universal project.

Keywords: Reality. Multiplicity. Everyday Life.

Resumen: El presente trabajo pretende pensar la realidad cotidiana como una dimensión en multiplicidad que se abre al diverso y a la diferencia. Para desarrollar esta cuestión, son problematizadas dos concepciones sobre la realidad: una que defiende que ésta puede ser comprendida como una unidad totalizable en su inmovilidad, y otra que considera por realidad una dinámica en movimiento siempre en vías de nuevas transformaciones. En la propuesta de seguir estos dos modelos de realidad, este trabajo se utiliza, como un cordón de Ariadna, de la acción de acompañar algunos usos que se han hecho, en los últimos dos milenios, de la imagen del Diablo. Al desdoblar esos usos diferentes en la conversación con las teorías de Platón, Hegel, Nietzsche, Deleuze y Guattari, este trabajo defiende que las realidades cotidianas son forjadas en encuentros inciertos a agitar mezclas que, debiendo en multiplicidad, no se afilian a un proyecto universal.

Palabras clave: Realidad. Multiplicidad. Cotidiano.

\footnotetext{
${ }^{1}$ Submetido em: 04 dez. 2018 - Aceito em: 11 fev. 2019 - Publicado em: 18 fev. 2019.

${ }^{2}$ Universidade Federal de Viçosa (UFV) - E-mail: simonini198@ gmail.com
} 
Raffaella Cerullo, também chamada de Lina e uma das principais personagens do romance "A Amiga Genial" (FERRANTE, 2015), escutava com pouca paciência Elena Greco, uma colega de infância que, ao fazer um curso de teologia, debatia-se em questionamentos sobre a verdadeira função do Espírito Santo na Santíssima Trindade. Em um de repente, Lina, já angustiada com os malabarismos teológicos da amiga, voltou-se para Elena dizendo que:

\begin{abstract}
Nós estamos voando sobre uma bola de fogo. A parte que resfriou flutua sobre a lava. Sobre esta parte construímos prédios, pontes e estradas. De vez em quando a lava sai do Vesúvio ou então provoca um terremoto que destrói tudo. Há micróbios por todo lado, que nos fazem adoecer e morrer. Há as guerras. Há uma miséria ao redor que nos torna todos ruins. A cada segundo pode acontecer alguma coisa que lhe fará sofrer de uma maneira que nunca haverá lágrimas suficientes. E você faz o quê? Um curso de teologia em que se esforça para entender o que é o Espírito Santo? Deixa pra lá, foi o Diabo que inventou o mundo, não o Pai, o Filho e o Espírito Santo (FERRANTE, 2015, p. 259).
\end{abstract}

Em seus argumentos, Lina sustentava que o nosso mundo nada mais era do que um risco camuflado em estabilidade. E se este vagante planeta, em cuja crosta habitamos, é uma experiência instável a se compor sobre uma solidez provisória, igualmente nossas vidas, à semelhança dessa terra frágil que se organiza sobre o fogo, podem desabar a qualquer instante, levadas em abruptos movimentos que têm o poder de arrastar qualquer pessoa, de um instante para outro, para um mundo em melancolia. E, por fim, Lina sentencia: Deus não se importa com o mundo, uma vez que este é consequência dos fazeres do Diabo.

O Diabo - e o reino que construiu para si - teve no século XIV, com Dante Alighieri, uma das suas mais famosas apresentações quando este descreveu os círculos concêntricos do Inferno no poema medieval "A Divina Comédia". Estes círculos tinham seu ponto de origem assinalado por um portal em que as almas condenadas à perene danação podiam ler a seguinte inscrição: "Por mim se vai ao círculo dolente; por mim se vai ao sofrimento eterno; por mim se vai à perdida gente. [...] Renunciai às esperanças, vós que entrais" (ALIGHIERI, 1981, p. 31). Portanto, o sofrimento, a agitação, o ranger de dentes e a total desesperança seriam condições da presença do e no Diabo, entidade que se colocava em contraposição à paz e serenidade da presença em Deus.

Por sua vez, nas considerações de Lina, o Diabo é apresentado igualmente como sendo expressão criadora, uma vez que concebe nosso mundo, ainda que para afirmar nele não uma garantia, mas a incerteza e a dissimilitude, já que "etimologicamente o dia-bólico separa, divide, aparta. Contrapõe-se ao sim-bólico, que sintetiza, reúne, unifica” (CORAZZA, 2002, p. 17). Mas quando seguimos entre diferentes expressões do Diabo, encontramos esse movimento criador - anunciado por Lina - presente em diversas representações. Baal, por exemplo, era uma entidade suméria relacionada à fertilidade e às forças vitais quando israelitas, no século IX a.C., passaram a chamar de Baal todas as divindades que qualificaram como falsos deuses. Se, com os israelitas, aquela entidade incorporou as representações da farsa e do erro, com o advento do Cristianismo, Baal passou a ser concebido como sendo um dos regentes do Inferno (SCHWARTZ, 2017). Contudo, em suas primeiras significações, Baal era uma experiência de multiplicação, de movimento produtor de vida. Igualmente Azazel, um anjo que no Livro de Enoque ${ }^{i}$ é um dos nomes relacionados ao Diabo, foi 
seduzido pela beleza das mulheres terrenas e com elas copulou, gerando filhos monstruosos que, por sua vez, foram exterminados por Deus quando do grande Dilúvio. Mas novamente o movimento criador e multiplicador surge, uma vez que Azazel era uma experiência tanto construtora - tendo iniciado os seres humanos no manejo dos metais, dos adornos, das pedras preciosas, das tintas - quanto também sexuada, prenhe de desejos e artífice da criação de vida no ato da procriação (RODRIGUES, 2004). Mas por ter se dedicado à terra e instrumentalizado os seres humanos para que, no manipular dos elementos naturais, se tornassem eles mesmos fabricantes de seu próprio mundo, sobre Azazel Deus repousou a seguinte condenação:

Amarra Azazel de mãos e pés e lança-o nas trevas! Cava um buraco no deserto de Dudael e atira-o ao fundo! Deposita pedras ásperas e pontiagudas por baixo dele e cobre-o de escuridão! Deixa-o permanecer lá para sempre e veda-lhe o rosto, para que não veja a luz! [...] Toda a terra está corrompida por causa das obras transmitidas por Azazel. A ele atribui todos os pecados! (RODRIGUES, 2004, p. 293).

$\mathrm{O}$ ato da criação tinha, pois, que ser uma virtude apenas de Deus e de nenhum outro ser: fosse humano, anjo e/ou diabo. Por sua vez, Ziedan (2015) apresentou Azazel de outra maneira, considerando-o como um símbolo da própria condição de dúvida e questionamento constantes a atormentar os seres. Estar à sombra de Azazel seria como exercitar uma dúvida metódica tal qual o fez Descartes (2004), quando, em ansiosa procura pela Verdade, passou a questionar as certezas e constâncias de tudo a seu redor. Nesse sentido, como propriedade de Azazel, a dúvida é uma experiência dia-bólica, uma vez que coloca movimento no pensamento, inserindo linhas interrogativas (tantas vezes incômodas e desassossegadas) onde antes se fixava, triunfante, um ponto final. É como narrado no Evangelho de Mateus, quando neste se justifica o quase afogamento do apóstolo Pedro pelo fato de o mesmo ter deixado que a dúvida tomasse seus pensamentos, não sustentando, assim, seu caminhar sobre as águas:

[...] veio Jesus ter com eles [os apóstolos], andando sobre o mar. E quando o viram andar sobre o mar, se turbaram dizendo: é, pois, um fantasma. E de medo começaram a gritar. Mas Jesus lhes falou imediatamente, dizendo: tende confiança, sou eu, não temais. E respondendo, Pedro lhe disse: Senhor, se tu és, manda-me que vá até onde tu estás por cima das águas. E ele lhe disse: vem. E descendo Pedro a barca, ia caminhando sobre a água para chegar a Jesus. Vendo, porém, que o vento era rijo, temeu, e quando se ia submergindo, gritou, dizendo: Senhor, põe-me a salvo. E no mesmo ponto Jesus, estendendo a mão, o tomou por ela e lhe disse: homem de pouca fé, por que duvidaste? (BIBLIA SAGRADA, 1975, MATEUS, 14:25-31).

Pode-se querer, a partir da dúvida, mover-se na busca pelo Absoluto - como pretendia Descartes -, ou cair em desespero por não encontrar mais certeza nos passos que se dá, como aconteceu com o apóstolo Pedro. Seja numa experiência ou noutra, a dúvida remete a uma cisão com um mundo garantido em seu projeto e propósito, o que faz com que, contrária a uma experiência de integração e síntese (dimensão simbólica), o Diabo seja colocado no campo do questionamento, da cisma, da dualidade (dimensão dia-bólica). Aquilo que se ergue como problematização e como dúvida consequentemente se expressa pela força de um tipo de oposição, e é nesse sentido que Corazza (2002) apresenta que as figuras do Diabo e do demônio, apesar de possuírem diferenças etimológicas ${ }^{\mathrm{ii}}$, acabaram por serem fundidas em 
uma mesma expressão, uma vez que, para se tornar um opositor, há a necessidade de igualmente ser astuto e inteligente para convencer e seduzir os adversários. Desta forma:

[...] demônio é gênio, espírito, inteligência. Sócrates tinha - ou Platão inventou que tinha - o seu daimon particular, com quem dialogava. A junção diabo/demônio começou a ocorrer com a Inquisição e fortaleceu-se com a invenção do inconsciente individual na modernidade (CORAZZA, 2002, p. 17).

A palavra demônio vem do latim daemonium que, por sua vez, deriva do grego daimónion ou daimon (CUNHA, 2010). Costa (2012, p. 175) considera que, para os gregos e os gnósticos cristãos, “daimon podia ser pensado como a própria divindade, o destino, o nume, o gênio, o conselho dos anjos, a voz interior, o espírito, o demônio". Sendo o daimon platônico uma entidade cheia de inteligência e de argúcia (pois "voz interior" do próprio Sócrates), ele parece comungar do mesmo movimento criador que assinalamos em Baal e Azazel. E o daimon, para além da alusão feita a Sócrates, assumiu na obra platônica tanto uma ação criativa quanto também uma ação dualista na produção de uma díade complementar: o mundo das Essências Perfeitas e o mundo das aparências ou cópias. Para Platão (2011), a realidade que vivenciamos cotidianamente é efeito do trabalho de uma mente inteligente (e, portanto, um daimon), denominada de demiurgo; palavra esta que vem a designar um artífice, um artesão da realidade. O demiurgo, no intuito de reproduzir a verdade e a beleza das Essências Perfeitas, apropriou-se de tudo que no universo se movia em caótica irregularidade e, tendo as Essências como arquetípica referência, criou ele o nosso mundo. Segundo Platão (2011, p. 93-94):

[...] temos que primeiro distinguir o seguinte: o que é aquilo que é sempre e não devém, sem nunca ser? Um pode ser apreendido pelo pensamento com o auxílio da razão, pois é inevitável. Ao invés, o segundo é objeto da opinião acompanhada da irracionalidade dos sentidos e, porque devém e se corrompe, não pode ser nunca. Ora, tudo aquilo que devém é inevitável que devenha por alguma causa, pois é impossível que alguma coisa devenha sem o contributo duma causa. Deste modo, o demiurgo põe os olhos no que é imutável e que utiliza como arquétipo, quando dá a forma e as propriedades ao que cria.

Desta maneira, a cosmogonia platônica também faz refrão à constatação de Lina: nosso mundo, nosso universo e, consequentemente nossa realidade cotidiana, seriam o efeito da ação de um daimon desejoso por criar para si um mundo que mimetizasse a Perfeição. Contudo, o mundo que o demiurgo inaugurou era semelhante - mas não idêntico - ao modelo de perfeição por ele vislumbrado; isto porque o que foi criado ficou igualmente marcado pelo movimento, pela ilusão, e, o pior de tudo, por falsas representações da própria cópia; falsificações estas que Platão (1991) definiu como sendo simulacros. Para o filósofo era, pois, necessário intuir nas cópias a perfeição das essências e, por sua vez, localizar e destruir os simulacros: aquelas expressões qualificadas como maléficas, pois, movimentando-se em pura diferença, em nada imitavam a Essência Perfeita ou as cópias dela multiplicadas.

Fosse no ato de tentar extrair um pouco dos indícios de pureza impressos nas cópias impuras; ou fosse denunciando o aberrante nos simulacros, negando-lhes legitimidade de existência; o projeto platônico se comprometeu com a proposta de superar o mundo demoniacamente engendrado (pois errante, instável, impermanente, falsificado) a fim de se atingir um acesso direto à perfeição que o demiurgo usou como modelo para sua imperfeita 
obra. $\mathrm{O}$ que nos conduz à reflexão de que, para Platão, a Verdade era uma experiência tão definida e finalizada que o exercício do pensar acabava por ser concebido não como um ato de criação, mas como a fiel reprodução de uma Verdade que, sem contradições, era imune às ilusões dos sentidos. O que fez com que toda a experiência da vida cotidiana fosse apreendida como enganosa, pois sujeita ao tormento cacofônico que pouco ou nada conseguia fazer audível o som eterno da canção pura.

Por motivos semelhantes aos narrados na cosmogonia platônica, os membros de um movimento medieval místico-religioso, denominados de Cátarosiii, negavam o mundo cotidiano, alegando que ele nada tinha de válido, pois era matéria; e a matéria, por sua vez, era veículo da degradação, da mudança e da morte. Para os Cátaros, o Diabo, quando expulso da presença de Deus, decidiu, a exemplo do demiurgo de Platão, edificar um mundo para si, criando seu universo a partir dos elementos pré-existentes e presentes em Deus (NELLI, 1980). Foi quando, ao engendrar os elementos da natureza (ar, terra, vento, água, tempo), o Diabo inventou a matéria, fabricou os corpos, concebeu o nosso mundo: mundo este que já nasceu corrompido, pois os elementos divinos que lhe serviram de inspiração criativa foram deturpados pela intervenção diabólica. Deus, porém, enquanto pureza e perfeição, em nada estava comprometido com os devires da matéria; por isso é que, para os Cátaros - também a exemplo do que sentenciou Lina - nosso mundo é mau e o Diabo é seu príncipe. Denunciavam, pois, que aquele que judeus e cristãos louvavam como sendo o Deus Criador ${ }^{\text {iv }}$, nada mais era do que o próprio Diabo. Assim, para os Cátaros, "era necessário libertar-se do Mal e do mundo material, esforçando-se para estabelecer o mínimo de contatos possíveis com eles, entregando-se à vida espiritual: viver no invisível e não no visível” (NELLI, 1980, p. 66).

Contudo, a ânsia de habitar mundos perfeitos e, por isso, sem movimento - como desejavam os Cátaros e igualmente os platônicos - era, para pensadores como Nietzsche, uma escolha pela morte e/ou pela vida impotente. Negando legitimidade ao que é da terra, do cotidiano, das lutas diárias, a fim de buscar a paralisia no Ideal, o que se empreende seria a negação da própria vida.

Atravessada por composições transitórias de forças, a existência, no entendimento de Nietzsche, é engendrada em potências criadoras-destruidoras sem começo assinalado ou fim determinado. Não é algo que se torna, mas algo que passa, que flui (NIETZSCHE, 1966). O fim de um mundo não seria, portanto, nada além de uma nova composição a anunciar novas combinações a partejarem novos mundos. É diante disso que temos que Nietzsche se opõe a Platão, aos Cristãos, aos Cátaros, a Descartes, a Hegel: a todos aqueles que, para ele, renegaram a vida, desqualificando o valor do movimento - do devir - para buscar o Absoluto, a Verdade, e a consequente cessação da existência, pois o Absoluto seria o ponto final de todo devir.

E se nos voltarmos aqui um pouco mais atentamente a Hegel, temos que ele empreendeu uma dinâmica "diabólica" semelhante à de Descartes: propôs a dúvida e o movimento como métodos para se pensar a Verdade. Isso porque, quando em sua dialética Hegel se refere ao devir, ele o compreende pela ótica daquilo que não é, mas que contribui para a realização do que é: o devir, então, é apresentado como um negativo, no sentido em 
que não é a Verdade, mas conduz a ela. Em Hegel, o movimento (o devir) é, pois, análogo à ação de lapidar um diamante para desvelar sua última e mais bela expressão, sendo que o Absoluto já está pressuposto tanto no diamante finalizado, quanto no movimento de purificálo. O que faz com que o Absoluto seja o próprio processo da vida, seja o processo do conhecimento, seja também "[...] Natureza e, de maneira toda especial, o Absoluto é Espírito, é Eticidade, é Estado, é o curso e o julgamento da História” (CIRNE-LIMA, 2012, p. 266), uma vez que a história do mundo pretende:

que o espírito alcance o saber do que é verdadeiramente e objetive esse saber, o realize, fazendo dele um mundo existente, e se manifeste objetivamente a si mesmo: os princípios dos espíritos dos povos, em uma necessária e gradual sucessão, não passam de momentos do único espírito universal, o qual, através deles, na história, se eleva e finaliza uma totalidade autocompreensiva (HEGEL, 2005, p. 15).

Desta maneira, se por um lado na dialética hegeliana a realidade é tomada por uma perspectiva processual, por outro lado Hegel também sustentava que existiria um sentido final a orientar esse movimento, no coroamento de uma grande síntese: a realização do Espírito Universal. Tal Espírito é o Absoluto "porque ele é a totalidade em movimento, porque ele é o Universo vivente e vivificante em sua totalidade circular" (CIRNE-LIMA, 2012, p. 267). A noção de "totalidade em movimento" ou "totalidade circular" é trabalhada em Cirne-Lima também como uma relação de síntese entre o movimento circular (que não produz história, pois retorna ao mesmo ponto) e o movimento linear e histórico (pois, submetido à flecha do tempo, é contingente e, portanto, não previsível). Para exemplificar sua reflexão, Cirne-Lima considera que um ciclista, ao guiar sua bicicleta, produz um movimento linear para frente por meio do movimento circular na roda que o carrega. Contudo, na dialética, essas duas dinâmicas em contradição (circularidade e linearidade):

[...] são superadas se e enquanto se opõem. São guardadas naquilo que têm de positivo. O que é isso? O ponto inextensivo - nem circular, nem linear -, que, ao se pôr em movimento, traça não só a circularidade da roda, como também a linearidade do trajeto histórico. O ponto em movimento, esse é a síntese entre tese e antítese. Esse ponto tem que ser pensado como o eterno momento presente, porque assim ele resgata todo o seu passado e antecipa todo o futuro. $\mathrm{O}$ eterno momento presente, inextensivo e atemporal, guarda dentro de si - aufghehoben - todas as contingências da história que já passou e do futuro que está por vir. [...] O Absoluto [...] é o ponto em movimento, o eterno momento presente (CIRNE-LIMA, 2012, p. 298).

Podemos, pois, problematizar que sendo o Absoluto o ponto inextensivo e atemporal a figurar como o "eterno momento presente", em que se encontra todo passado e todo futuro e se considerarmos também que o conceito de eternidade se refere à ausência de tempo (e, portanto, ausência de toda mudança e/ou transformação) - o movimento seria, na dialética hegeliana, uma ilusão. Isso porque o Absoluto, como ponto inextensivo de eterno presente, já estaria suposto no devir, sendo ele o sujeito oculto da lógica dialética (tese, antítese, síntese): “o Absoluto é ser, o Absoluto é nada, o Absoluto é devir" (CIRNE-LIMA, 2012, p. 273). É nesse sentido que Cirne-Lima (2012) igualmente sustenta que o sistema hegeliano é um pensamento religioso por excelência, em que o Absoluto (Deus) está em tudo: ele é essência, aparência, identidade, diferença, contradição; está, sem restrição, em todos os lugares; ele é a roda sob a qual se inscreve o trajeto da história. Com o Absoluto, estaria indicada a 
construção de um sistema de totalização a propor uma síntese unificadora de todas as temporalidades e, portanto, de todo movimento. Seria ele "movimento e, ainda assim, ausência de movimento. Não há espaço, não há tempo, e, portanto, nada se move, apenas existe" (MOORE; CAMPBELL, 2014, p. 14).

Fazendo ressonância a tal constatação, Châtelet (1985, p. 15) denunciou as pretensões universalistas da dialética hegeliana quando problematiza que:

A dialética, como estrutura do discurso, é o processo pelo qual o filósofo pensa assegurar a transparência integral do Ser, dialética essa que tem a mágica virtude de estabelecer a correspondência correta entre os momentos do pensamento e a diversidade sistemática da existência. Como numa cena de tragédia, ela [a dialética] insiste na presença das contradições. [...] Ela, que pretende eliminar todos os pressupostos, pressupõe a realidade (isto é, a possibilidade) de uma completa revelação da verdade do existente. Deus compreendeu outrora que, se queria sobreviver, deveria descer à terra e fazer-se Razão. Com Platão, com o Cristianismo, falou grego. Com Hegel, falou a gíria dialética.

Portanto, se Deus foi concebido como o Absoluto, tal qual argumentaram Châtelet (1985) e Cirne-Lima (2012) sobre o pensamento de Hegel, podemos pensar que o Diabo é copartícipe desse Absoluto e pode ser entendido como o próprio movimento dialético a sustentar uma luta de opostos que só cessará suas contradições quando do Fim dos Tempos: pois o universo encontraria seu ponto de não contradição - e consequentemente de não movimento - na realização do Espírito Universal.

Na trilha indicada pela crítica de Châtelet, temos que quando Deleuze (1976) se propôs a debater sobre as intensidades em devir, não se posicionou ao lado de Platão ou Hegel, mas ao lado de Nietzsche. E, assim como este último filósofo, evitou envolver-se com a dialética ${ }^{\mathrm{v}}$ a fim de seguir por um outro caminho, um outro processo pensado pela positividade do devir - devir que não se constituiria enquanto negação de uma síntese em vias de uma nova síntese de nível superior, mas sim como potência de multiplicidades e de experimentações. Deleuze (1976), portanto, pensou a dialética hegeliana não como um erro, mas como uma insensatez. Insensatez esta que consistiria em valorizar a perspectiva de um movimento em direção a uma condição de não-criação. E acrescentou que:

A dialética hegeliana é uma reflexão sobre a diferença, mas inverte sua imagem.
Substitui a afirmação da diferença enquanto tal pela negação do que difere; a
afirmação de si pela negação do outro; a afirmação da afirmação pela famosa
negação da negação. [...] A oposição colocada no lugar da diferença é também o
triunfo das forças reativas que encontram na vontade de nada o princípio que lhes
corresponde. [...] Em toda parte as paixões tristes; a consciência infeliz é o sujeito
de toda dialética. A dialética é primeiramente o pensamento do homem teórico em
reação contra a vida, que pretende julgar a vida, limitá-la, medi-la (DELEUZE,
1976, p. 163).

Abandonando Hegel, Deleuze compreendeu o devir como afirmação na diferença e não como subproduto de uma negação em vias a um maior aperfeiçoamento a indicar um progresso, uma condição de plena realização, um Absoluto. Diante de tais argumentações, um mundo em devir não pode ser tomado como uma direção pré-definida - como um vir a ser "algo" - já que não é um termo que devém em outro, mas cada um que encontra o outro, num devir singular que se dá "entre" os dois termos da relação e que possui sua própria direção 
(DELEUZE; PARNET, 1987). Assim, o devir de um mundo não se destinaria a realizar uma ordem superior; não se organizaria enquanto um jogo de palavras cruzadas onde tudo se encaixa. O que está em devir comprometer-se-ia com encontros, misturas, ordens transitórias e produções aberrantes; e nessa condição não existiria um modelo prévio a compor com os fluxos; não existiria um arquétipo de perfeição a referendar o movimento passado, presente e futuro do mundo.

Portanto, para Nietzsche e Deleuze, o Espírito Universal não sintetizaria todos os destinos da realidade. Não seria ele o termo de todos os processos ou o enlace de todas as temporalidades, pois o que se encontra no "fim" não acolheria um ponto final ou um "eterno momento presente", mas a vírgula da errância, da continuidade; a afirmação da afirmação, diferença da diferença, composições múltiplas a construírem possibilidades, inspirações, experimentações no oferecer um "sim" a um mundo impensado até mesmo por Deus vi . É como narrou Clarisse Lispector, no início de seu livro "A Hora da Estrela":

tudo no mundo começou com um sim. Uma molécula disse sim a outra molécula e nasceu a vida. Mas antes da pré-história havia a pré-história da pré-história e havia o nunca e havia o sim. Sempre houve. Não sei o quê, mas sei que o universo jamais começou (LISPECTOR, 1998, p. 11).

As palavras de Lispector, por sua vez, parecem fazer ressonância com as de Nietzsche, quando este declarou que, se a vida está comprometida com uma circularidade, esta é criadora, pois sempre aberta a "um novo começo, um jogo, uma roda a girar por si mesma, um primeiro movimento, um sagrado dizer-sim. Sim para o jogo da criação, meus irmãos, é preciso um sagrado dizer-sim" (NIETZSCHE, 2011, p. 29). Nesse sentido, assumimos aqui uma terceira compreensão possível da dimensão diabólica: não como edificadora de um mundo apresentado como pastiche da Essência Perfeita; não como um movimento de contradições em vias de realizar o Espírito Universal (Deus); mas como um "sim"; como uma condição de diferença, uma totalidade não totalizável (DELEUZE; GUATTARI, 2010), ou, como afirmou Corazza (2002, p. 17), “desde aí, o diabólico pode ser pensado como multiplicidade sem unidade".

O conceito de "multiplicidade" foi trabalhado por Deleuze e Guattari (1995) como uma totalidade que, à diferença do Absoluto hegeliano, não se fecha em uma integrativa unidade de temporalidades e movimentos. Se a dialética hegeliana é o método a ser usado para subir da multiplicidade para a unidade (CIRNE-LIMA, 2012), Deleuze e Guattari (1995) propõem, em contraste, que a multiplicidade não se refere ao plural em vias a uma síntese unificadora, mas a dimensões animadas em agenciamentos que, no fomento de diferentes e anárquicas conexões, não têm seus destinos pré-definidos na eternidade do Espírito Universal. A cada novo arranjo haveria sempre a possibilidade de criação de uma inédita perspectiva; de um novo universo a se estabilizar (ou não) em singulares ordenações. Nessa perspectiva, o fato de um arranjo conectivo vir a morrer em um beco sem saída ou se fixar em uma territorialização identitária, não definiria, por sua vez, um ponto final ou de acabamento do mundo, mas apenas indicaria que um processo específico diminuiu e/ou não mais manteve ativas as conexões que o vitalizavam. Contudo, outros processos se ramificariam, correndo 
vertical, horizontal, em paralelo e/ou transversalmente, no ativar de outras linhas, outros movimentos, outros mundos.

Assim, em Deleuze e Guattari (1995) a multiplicidade não se refere a um coletivo de elementos em relação causal, mas a uma circulação de estados, de processos, de forças em ampliação ou constrição, em que dançam significações plurais. Essa multiplicidade, que foi considerada por Corazza (2002) como sendo diabólica - pois não redutível a uma unidade centralizadora - e por nós como sendo um experimental "sim", é igualmente experiência de oportunização de mundos. Mundos estes ainda indefinidos, pois inventados em meio a arranjos incertos, tantas vezes angustiantes, mas que podem oferecer passagem a diferentes sensibilidades.

Talvez tenha sido nessa perspectiva que Robert Musil (2018) intuiu que para cada "senso de realidade", para cada mundo concreto em que um sujeito ou grupo referencia seus passos, atitudes e perspectivas, deva igualmente existir um "senso de possibilidade". Segundo ele, quem possui um senso de possibilidade:

[...] não diz, por exemplo: aqui aconteceu, vai acontecer, tem que acontecer isto ou aquilo; mas inventa: aqui poderia, deveria ou teria de acontecer isto ou aquilo; e se lhe explicarmos que uma coisa é como é, ele pensa: bem, provavelmente também poderia ser de outro modo. Assim, o senso de possibilidade poderia ser definido como a capacidade de pensar tudo aquilo que também poderia ser, e não julgar que aquilo que é seja mais importante do que aquilo que não é (MUSIL, 2018, p. 24).

Ou seja, se a validação de uma realidade tende a ser afirmada pela repetição aparentemente infinita de regras, padrões, referências e destinos, isso não suprime a oportunidade de "[...] chegar uma pessoa para a qual uma coisa real não signifique mais que o imaginado. Será ela quem dará sentido e destinação às novas possibilidades, que há de provocar" (MUSIL, 2018, p. 25). Provocar, pois, a produção de "para-lógicas" que, mesmo não sendo consideradas legítimas dentro da senda de um tipo de racionalidade que se pretende a única possível, insistem em se produzir como viáveis.

Contudo, é importante salientar que essas novas possibilidades não estariam prédefinidas em suas trajetórias, como uma árvore inteira já se encontra adormecida dentro da semente antes mesmo de esta germinar. Ao contrário disso, novas possibilidades têm, para seguir os argumentos de Musil, que ser provocadas, inventadas, agenciadas. E agenciamentos só existem em movimento, na composição em multiplicidade de um novo arranjo; na fecundação de um "senso de possibilidade". Mas do mesmo modo que a multiplicidade não é traduzível a um lugar específico, os agenciamentos que a atravessam dizem respeito mais a uma complexa espacialização do que à descrição de um definível lugar. Por isso nos associamos a Massey (2008), quando esta considera o espaço como produto de interrelações tanto macro quanto microscópicas; sendo igualmente dimensão em multiplicidade, em que distintas trajetórias coexistem. Para a referida autora, multiplicidade e espaço são processos co-constituídos e sempre em construção; estão sempre no processo de fazer-se, sendo abertos num devir sem Juízo Final. Desta maneira:

Nesse espaço aberto interacional há sempre conexões ainda por serem feitas, justaposições ainda a desabrochar em interação (ou não, pois nem todas as conexões potenciais têm que ser estabelecidas), relações que podem ou não ser realizadas. [...] 
Um espaço, então, que não é nem recipiente para identidades sempre-já constituídas, nem um holismo completamente fechado. É um espaço de resultados imprevisíveis e de ligações ausentes. Para que um futuro seja aberto, o espaço também deve sê-lo (MASSEY, 2008, p. 32).

O espaço é, pois, tomado aqui como uma dimensão existencial cuja potência se afirma na força flexível de seus agenciamentos; agenciamentos estes assumidos, especialmente na obra de Félix Guattari (1992), como um espaço intensivo em que entram em relação elementos diversos que, muitas vezes, não têm a priori nenhuma ligação entre si; um espaço que, como bem definiu Massey (2008), é de "ligações ausentes". Nesta perspectiva, os agenciamentos ativam (e são ativados em) uma relação vibrátil que produz uma frequência, um ritmo, mas não necessariamente constitui um lugar em cuja especificidade os elementos se apresentariam ligados numa lógica causal, temporal ou geográfica. Contudo, a frequência intensiva ativada em um agenciamento produz potenciais sensibilidades e cognições que oportunizam expressões existenciais a movimentarem outros sensos de realidade e outros campos de possibilidades. Algumas destas últimas podem vir inclusive a se estabilizar e mesmo se cronificar, transformando-se em lugares de segura redundância (de valores, de práticas, de desejos, de sonhos), configurando uma vida cotidiana que se apresenta sustentada na mimese ritualística de um dia a dia aparentemente sempre igual. Contudo, consideramos aqui que um lugar é apenas a estabilização de um território (provisório) num espaço em "diabólica" multiplicidade, pois movente, não plenamente totalizável e sem fim definido ou começo assinalado. A vida, fluindo em processo de contínuo deslocamento a desconhecer teleologias absolutas, seria animada por dinâmicas em diferentes acelerações e paralisias; o que faz do existir cotidiano uma experiência para além da repetição sem criação, pois envolvida em riscos de repentinos movimentos.

Ilustrando essa problematização, temos que no final do século XX o grupo musical Green Day (1997) lançou um vídeo clipe com a canção Redundant ${ }^{v i i}$. Este se inicia com um jornal sendo jogado em uma sala para, em seguida, uma mulher entrar no cômodo, pegá-lo e sair andando. Durante todo o clipe da canção, a mesma cena da mulher com o jornal se repete. Ao final da música, porém, o vocalista do grupo pega o jornal do chão antes que a mulher o faça e quando esta chega à sala e verifica que o mesmo não está "como sempre" ali, solta um grito onde se mesclam paralisia e medo. A repetição do ato de pegar o jornal se estabeleceu para ela como o lugar de verdade em um mundo no qual se reconhecia segura na constância que habitava. Mas, de repente, sua territorialidade identitária foi abalada quando um sutil deslocar instaurou um "senso de possibilidade", deixando-a vislumbrar o risco do inusitado em seu viver cotidiano.

Nessa produção de constâncias cotidianas a demarcarem lugares de segurança, temos que um determinado valor familiar e/ou social é igualmente um lugar que se repete, atravessando as gerações e produzindo verdades que oferecem consistência à territorialidade histórica de um grupo e/ou de um indivíduo. São lugares que, por temerem a amplitude dos espaços em multiplicidade, fecham-se tantas vezes em endurecidos discursos de essências e exclusão do que, estando em devir, ameaça alguma específica estabilidade conquistada. Contudo, tais redundâncias cotidianas, a organizarem verdades de um mundo, não foram 
eternamente dadas, mas construídas. A essas repetições a edificarem provisórias consistências Deleuze e Guattari (1997) nomearam de ritornelos.

Capturaram eles esta concepção do universo da música onde, em seu aspecto estritamente melódico, ritornelo significa um estribilho ou um prelúdio que se repete no decorrer de uma composição, sendo, portanto, um conceito que se refere ao retorno de um tema, a um refrão. Todavia, fazendo tal conceito "funcionar" em outras dimensões que não apenas as da música, os referidos autores significaram o ritornelo como atuando em uma dimensão de multiplicidade, sendo, então, compreendido como um encadeamento de componentes heterogêneos que produz um território existencial. Uma vez que, "num sentido geral, chamamos de ritornelo todo conjunto de matérias de expressão que traça um território, e que se desenvolve em motivos territoriais, em paisagens territoriais" (DELEUZE; GUATTARI, 1997, p. 132), os ritornelos emergem de estabilizações em espaços moventes e se comprometem com territorializações que podem ser relativas, de acordo com Guattari e Rolnik (2005, p. 388):

[...] tanto a um espaço vivido, quanto a um sistema percebido no seio do qual um sujeito se sente "em casa". O território é sinônimo de apropriação, de subjetivação fechada sobre si mesma. Ele é o conjunto dos projetos e das representações nos quais vai desembocar, pragmaticamente, toda uma série de comportamentos, de investimentos, nos tempos e nos espaços sociais, culturais, estéticos e cognitivos.

Composto em multiplicidade, o conceito de território na obra de Deleuze e Guattari é amplo, sendo muito mais do que a descrição de um lugar físico, estendendo-se também à dinâmica dos agenciamentos e, consequentemente, à multiplicidade, ao universo das relações, aos devires, à produção de ritmos a se repetirem e igualmente se descompassarem. No momento, pois, em que cada território não é exterior às multiplicidades e ritmos que o constitui, um seguro lar pode repentinamente se intensificar em terra estrangeira frente à composição vibrátil de novos agenciamentos. Dessa forma, se diferentes ordenações emergentes nos ritornelos promovem constâncias que ritmizam, num campo intensivo, políticas, sexualidades, economias, estéticas, dentre outras; estas, por sua vez, não se coadunam com a produção de um estado de imutável verdade que aniquilaria a legitimidade da composição de outros ritmos, de outras experimentações e paisagens existenciais.

Assim, é importante frisar que, enquanto dinâmica movente, o ritornelo não é um lugar definido, mas agenciamentos a montarem, desmontarem e remontarem um lugar. Ele é uma dimensão de encontros e não de rígida fixidez, sendo que "no ritornelo, o que volta não é o elemento, não é a forma, nem a sonoridade [...], o que volta é a potência de fazer música; a potência de fazer e desfazer lugares" (FERRAZ, 2005, p. 39). No mesmo ato em que inaugura uma novidade expressiva, um novo ritornelo pode vir a colocar em risco a consistência e legitimidade de territorialidades já estabelecidas, fomentando "[...] zonas de turbulência; terrenos que muitas vezes podem ser a interseção de dois ou mais terrenos [...]: harmonia vagante" (FERRAZ, 2005, p. 40). Ao compreendemos a "harmonia" não como uma dimensão ausente de conflitos, mas um agenciamento que, estabilizando-se como território, cria uma possível coordenada existencial; pensamos, então, que o termo "harmonia vagante" se torna aqui uma bela expressão para descrever a vida cotidiana. Vida esta engendrada em mundos em movimento que, todavia, não devem ser considerados como meros pontos de 
vista ou como variações representacionais de uma estática realidade pré-definida, mas sim como a invenção de novas enunciações:

[...] uma produção de novas coordenadas, uma autocoordenação, uma autorreferenciação. [...] Essas entidades obviamente produzem uma visão do mundo; elas produzem um mundo, elas produzem universos de referência que possuem suas próprias lógicas da mesma maneira que um músico como Debussy, de certo modo, inventou um novo tipo de relacionamento de escrita musical, um novo tipo de escala, um novo tipo de linha harmônica e melódica e, repentinamente, produziu novos universos e fertilizou uma série inteira de filos maquínicos para o futuro da música. Isto é produção de universo, uma produção de enunciação (GUATTARI, 1998, p. 220 - tradução nossa).

O que faz com que, para Guattari (1986), cada ritmo existencial que venha a animar uma produção cotidiana de realidade se constitua também numa trajetória com suas intensidades, seus compassos e agenciamentos a privilegiarem diferentes modos de existência a plurificarem a vida. Assim, se os processos, em agenciamento, dão ritmo a diferentes ritornelos existenciais, estes estabilizam mundos que não existem em separado dos agenciamentos que desenham suas tramas. E se uma realidade não é independente das multiplicidades que a engendram (em suas ritmações sociais, econômicas, políticas, educacionais, emocionais, psíquicas...), ela também deixa de ser concebida enquanto experiência unicamente fundamentada em algum princípio gerador que se pretenda a uma síntese totalizadora dos movimentos da existência.

Pensadas como devindo em multiplicidade, as realidades cotidianas não surgiriam, portanto, por partenogênese, mas em meio a dinâmicas vivas de choques, conflitos, núpcias, dúvidas, (des)encontros, questionamentos e fecundações..., tudo isso agenciado em um diabólico "sim" não filiado a um "eterno momento presente", a um destino universal, a alguma redentora moralidade ou tributário de um ponto final.

\section{Referências}

ALIGHIERI, Dante. A Divina Comédia. São Paulo: Abril Cultural, 1981.

BÍBLIA SAGRADA. Rio de Janeiro: Barsa, 1975.

CHÂTELET, François. O pensamento de Hegel. Lisboa: Editorial Presença, 1985.

CIRNE-LIMA, Carlos. O absoluto e o sistema. In: LUFT, Eduardo; CIRNE-LIMA, Carlos. Ideia e movimento. Rio de Janeiro: Civilização Brasileira, 2012.

CORAZZA, Sandra Mara. Para uma filosofia do Inferno na Educação: Nietzsche, Deleuze e outros malditos afins. Belo Horizonte: Autêntica: 2002.

COSTA, Alexandre. Heráclito: fragmentos contextualizados. São Paulo: Odysseus, 2012.

CUNHA, Antônio Geraldo da. Dicionário etimológico da língua portuguesa. Rio de Janeiro: Lexikon, 4. ed., 2010. 
DELEUZE, Gilles. Nietzsche e a filosofia. Rio de Janeiro: Editora Rio, 1976.

DELEUZE, Gilles; GUATTARI, Félix. Mil Platôs. São Paulo: Ed. 34, v. 1, 1995.

DELEUZE, Gilles; GUATTARI, Félix. Mil Platôs. São Paulo: Ed. 34, v. 4, 1997.

DELEUZE, Gilles; GUATTARI, Félix. O Anti-Édipo. São Paulo: Ed. 34, 2010.

DELEUZE, Gilles; PARNET, Claire. Dialogues. New York: Columbia University Press, 1987.

DESCARTES, René. O discurso do Método. São Paulo: Nova Cultura, 2004.

FERRANTE, Elena. A amiga genial. São Paulo: Biblioteca Azul, 2015.

FERRAZ, Silvio. Livro das sonoridades: notas dispersas sobre composição. Rio de Janeiro: 7 Letras, 2005.

GREEN DAY. Redundant. Nimrod. Warner, 1997. 1CD, Faixa 4.

GUATTARI, Félix. As novas alianças: movimentos sociais \& movimentos alternativos - um debate com Félix Guattari. Desvios. São Paulo: Paz e Terra, n. 5, março 1986.

GUATTARI, Félix. Caosmose: um novo paradigma estético. São Paulo: Ed. 34, 1992.

GUATTARI, Félix. Pragmatic/Machinic: discussion with Felix Guattari (19 March 1985). In: STIVALE, Charles J. The two-fold thought of Deleuze and Guattari. New York: Guilford, 1998.

GUATTARI, Félix; ROLNIK, Suely. Micropolítica: cartografias do desejo. Petrópolis: Vozes, 7. ed., 2005.

HEGEL, Georg Wilhelm Friedrich. Hegel. São Paulo: Nova Cultural, 2015.

LAWRENCE, David Herbert. O trabalho da criação. In: BLAKE, William; LAWRENCE, David Herbert. Tudo que vive é sagrado. Belo Horizonte: Crisálida, 2001.

LISPECTOR, Clarice. A hora da estrela. Rio de Janeiro: Rocco, 1998.

MASSEY, Doreen. Pelo espaço: uma nova política da espacialidade. Rio de Janeiro:

Bertrand Brasil, 2008.

MOORE, Alan; CAMPBELL, Eddie. Do Inferno. São Paulo: Veneta, 2014.

MUSIL, Robert. O homem sem qualidades. Rio de Janeiro: Nova Fronteira (Biblioteca Áurea), 2018.

NELLI, René. Os Cátaros. Lisboa: Edições 70, 1980. 
NIETZSCHE, Friedrich. Assim falou Zaratustra. São Paulo: Companhia das Letras, 2011.

NIETZSCHE, Friedrich. Vontade de potência. Rio de Janeiro: Ediouro, 1966.

PLATÃO. Sofista. São Paulo: Nova Cultural, 1991.

PLATÃO. Timeu-Crítias. Coimbra/Portugal: Centro de Estudos Clássicos e Humanísticos, 2011.

RODRIGUES, Cláudio J. A. Apócrifos da Bíblia e Pseudoepígrafos. São Paulo: Novo Século, 2004.

SCHWARTZ, Jorge (Org.). Borges babilônico: uma enciclopédia. São Paulo: Companhia das Letras, 2017.

ZIEDAN, Youssef. Azazel. Rio de Janeiro: Record, 2015.

\section{Notas}

\footnotetext{
' Livro apócrifo supostamente escrito em torno de 200 a.C e atribuído a Enoque, um ancestral de Noé. Nele são indicadas profecias, além de descrições sobre o destino dos anjos (denominados de Vigilantes) que abandonaram sua morada celestial para viverem entre os seres humanos.

ii $\mathrm{O}$ conceito de Diabo fala de uma entidade adversária que cultiva um movimento de oposição; enquanto o conceito de demônio se refere a uma entidade inteligente, astuta.

iii A palavra Cátaro (que vem a significar puro) começou a ser utilizada na Itália em torno do ano de 1030 d.C., sendo que a igreja cátara se firmaria de forma significativa no sul da França, vindo a desparecer completamente (por ação violenta da Igreja Católica e de seus caçadores de heréticos) no século XIV (NELLI, 1980).

${ }^{\text {iv }}$ Pois tudo o que cria, só cria na produção de um movimento; e o que está em movimento não pode sustentar em si a Perfeição.

" Segundo Deleuze (1976, p. 162), "três idéias definem a dialética: a ideia de um poder do negativo como princípio teórico que se manifesta na oposição e na contradição; a ideia de um valor do sofrimento e da tristeza, a valorização das 'paixões tristes', como princípio prático que se manifesta na cisão, no dilaceramento; a ideia da positividade como produto teórico e prático da própria negação".

vi "Deus é um grande impulso, maravilhoso, misterioso, magnífico, mas ele não sabe nada de antemão. Seu impulso toma forma na carne, e veja! é criação! Deus olha-se nela admirado, pela primeira vez. Veja! Lá está uma criatura, formada! Que estranho! Deixe-me pensar sobre isso! Deixe-me formar uma ideia!" (LAWRENCE, 2001, p. 229).

vii $\mathrm{O}$ vídeo clipe pode ser assistido em http://www.youtube.com/watch?v=wRE4zP826yA. Acesso em: $01 \mathrm{dez}$. 2018.
} 